\title{
Conference Paper \\ Comparative Assessment of an Innovative Dry-Cooled CSP System
}

\author{
Andreas Poullikkas, ${ }^{1,2}$ Ioannis Hadjipaschalis, ${ }^{2}$ and George Kourtis ${ }^{2}$ \\ ${ }^{1}$ American University of Sharjah, P.O. Box 26666, Sharjah, UAE \\ ${ }^{2}$ Electricity Authority of Cyprus, P.O. Box 24506, 1399 Nicosia, Cyprus
}

Correspondence should be addressed to Andreas Poullikkas; apoullik@eac.com.cy

Received 23 October 2012; Accepted 14 February 2013

Academic Editors: Y. Al-Assaf, P. Demokritou, and C. Sourkounis

This Conference Paper is based on a presentation given by Ioannis Hadjipaschalis at "Power Options for the Eastern Mediterranean Region" held from 19 November 2012 to 21 November 2012 in Limassol, Cyprus.

Copyright (C) 2013 Andreas Poullikkas et al. This is an open access article distributed under the Creative Commons Attribution License, which permits unrestricted use, distribution, and reproduction in any medium, provided the original work is properly cited.

\begin{abstract}
A comparative optimization assessment is carried out in order to identify the competitiveness of an innovative modular aircooled condenser (MACC) system in relation to conventional water- or air-cooled condensers. Specifically, the technoeconomic performance of the combined cycle gas turbine (CCGT) technology, the parabolic trough concentrated solar power (CSP) technology, and the solar tower CSP technology are compared when all are integrated (a) with a MACC condenser of an optimum tube geometry and size, (b) with a conventional water-cooled condenser, and (c) with a conventional dry-cooled condenser. The comparison is performed across three different solar potential levels. The simulations are carried out using an optimization model based on the IPP v2.1 algorithm for the calculation of the electricity unit cost and other financial indicators of each technology under investigation. The results demonstrate that, under certain parameters, the investigated MACC condenser system can become a cost-competitive alternative to water- or dry-cooled condensers in various solar potential environments.
\end{abstract}

\section{Introduction}

Current concentrated solar power (CSP) systems utilize water- or air-cooled condensers in a conventional Rankine cycle for electricity generation. The condenser performance is a key factor affecting the overall generation efficiency since it determines steam output temperature and pressure and thus the total amount of work done by the steam turbine. The utilization of water-cooled condensers, although effective, is constrained by the need for water availability in the immediate plant location. On the other hand, conventional air-cooled condensers, which do not necessitate the presence of a water source, are not as effective because they cannot maintain optimum condenser pressure and temperature and are unresponsive to daily variations in ambient temperature. This may translate to increased fan power consumption and lower CSP system efficiency [1-6].

In order to overcome the technical limitations of conventional air-cooled condensers, the MACCSol research project
[7], partly funded by the European Commission, provides an innovative industry solution through a new dry-cooling approach for multi-MWe-sized CSP systems. The consortium of project partners consists of three universities and four industrial partners. The universities are the University of Limerick in Ireland, the University of Erlangen in Germany, and the Universita Degli Studi di Perugia in Italy. The industrial partners involved are R\&R Mechanical Ltd. in Ireland, Torresol Energy Investments Ltd. in Spain, AuBren Ltd. in Ireland, and the Electricity Authority of Cyprus.

The primary objective of the MACCSol project is the development and verification of an innovative modular aircooled condenser (MACC) system. If successful, this innovative technology will remove a significant barrier to the deployment of CSP systems in desert and arid areas and thus assist the EU in achieving its 2020 renewable energy contribution targets [8-10]. It will also ultimately enable CSP systems to increase net power output and reduce costs compared to existing dry-cooled systems. The completed 


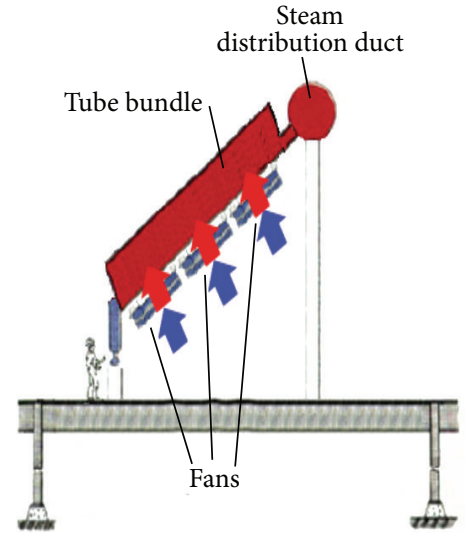

(a)

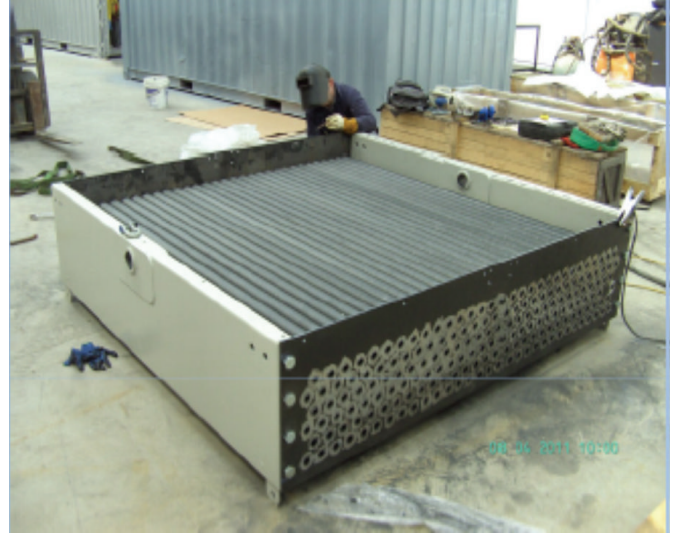

(b)

FIgURE 1: Typical MACC module arrangement (a) and tube bundle (b).

MACC system will incorporate sensors which will detect changes in temperature, ambient wind, and fan flow rate and control algorithms, which will communicate with these sensors to continuously vary fan speed. It will therefore maintain optimum condenser pressure and temperature irrespective of ambient conditions. As a result, steam turbine outlet conditions will always be optimized, thus maximizing power output and reducing operating costs. Also, because the MACC system will be a modular design, installation and maintenance costs will be significantly reduced.

Prior to its commercialization, the MACC system performance first needs to be monitored and optimized at both module and system levels. The optimization process involves numerical simulations, analytical modeling, physical scale modeling, and measurements on full-scale prototypes. The effects of all design options are to be assessed using thermodynamic models, while technoeconomic modeling will assess the lifetime cost implications of various design options of MACC systems. Finally, to prove the merits of the optimized MACC design, full-scale testing in an operational steam power plant will be performed.

A typical MACC module, with a length and width of $2 \mathrm{~m}$ by $2 \mathrm{~m}$, is shown in Figure 1. The module is basically made up of a $1 \mathrm{~m}$ diameter fan blowing air either in induced or forced draft mode across an array of condenser tubes, located in the tube bundle section of the module, shown in Figure 1(b), through which the output steam of the turbine flows.

The optimum MACC system size will consist of multiple modules, the exact number of which needs to be identified. In addition, the optimum MACC system configuration will correspond to a specific tube geometry design consisting of a unique set of tube rows, columns, and taxonomy.

In this work, a technical and economic comparative optimization assessment is carried out in order to identify the competitiveness of the optimum MACC system in relation to conventional dry-cooled or water-cooled condensers. Specifically, the techno-economic performance of the CCGT technology, the parabolic trough CSP (PT-CSP) technology, and the solar tower CSP (ST-CSP) technology are compared when all are integrated (a) with a MACC condenser of an optimum tube geometry and size, (b) with a conventional water-cooled condenser, and (c) with a conventional drycooled condenser.

In Section 2, the methodology and the software optimization tool that are used for the comparative optimization assessment are described. Then, the input data used in the analysis and the scenarios investigated are presented in Section 3. The results of the comparative optimization assessment are discussed in Section 4, while the conclusions are summarized in Section 5.

\section{Methodology and Simulation Procedure}

In order to perform the technical and economic comparative optimization assessment of the MACC system competitiveness compared to conventional dry-cooled or water-cooled condensers, the optimum MACC system tube geometry and size has to be first identified. The optimum MACC system geometry and size essentially incurs the lowest plant electricity unit cost because it corresponds to the optimum tradeoff between increased plant operating costs (associated with high MACC system fan speeds) and increased plant capital costs (associated with high heat transfer surface area and essentially MACC system size) [11, 12]. The optimum MACC system identification analysis has already been the scope of work of previous studies $[13,14]$, which were conducted on seventeen individual MACC system configurations with different tube geometries and on a total of eight different MACC sizes. The analysis has shown that the plate-finned MACC system geometry is the optimum geometry, with an optimum size of 955 modules [14], and will be used in the current comparative optimization assessment analysis.

For the purposes of this analysis, the operation of the CSP technology is simulated and the electricity unit cost is calculated based on the following algorithm: (a) calculation of solar radiation in plane of parabolic trough solar field, (b) calculation of electrical energy delivered by the CSP technology, (c) calculation of system losses, (d) calculation of electrical energy delivered to the grid, (e) calculation of required area for parabolic trough solar field, (f) calculation 
of required area for the installation of the solar thermal power plant, and (g) calculation of electricity unit cost assuming that the initial investment year is year 0 ; the costs are given in year 0 terms; thus any inflation rate (or the escalation rate) is applied from year 1 onwards, and the timing of cash flows occurs at the end of the year.

In order to perform the simulations required for the above optimization analysis of the electricity generation technologies, that is, the CCGT, the PT-CSP, and the STCSP technologies, the IPP v2.1 software tool is employed [15]. The software emerged from a continued research and development in the field of software development for the needs of power industry. This user-friendly software tool, the flowchart of which is shown in Figure 2, can be used for the selection of an appropriate least cost power generation technology in competitive electricity markets.

The software takes into account the capital cost, the fuel consumption and cost, the operation cost, the maintenance cost, the plant load factor, and so forth. All costs are discounted to a reference date at a given discount rate. Each run can handle 50 different candidate schemes simultaneously. Based on the above input parameters for each candidate technology, the algorithm calculates the least cost power generation configuration in real prices and the ranking order of the candidate schemes. The technical and economic parameters of each candidate power generation technology are taken into account based on the cost function:

$$
\begin{gathered}
\min \left(\frac{\partial c}{\partial k}\right) \\
=\min \left\{\left(\sum _ { j = 0 } ^ { N } \left[\left(\frac{\partial C_{C j}}{\partial k}+\frac{\partial C_{F j}}{\partial k}+\frac{\partial C_{\mathrm{OMFj}}}{\partial k}+\frac{\partial C_{\mathrm{OMVj}}}{\partial k}\right)\right.\right.\right. \\
\left.\left.\times\left((1+i)^{j}\right)^{-1}\right]\right) \\
\left.\times\left(\sum_{j=0}^{N}\left[\frac{\partial P_{j} / \partial k}{(1+i)^{j}}\right]\right)^{-1}\right\}
\end{gathered}
$$

where $c$ is the final cost of electricity in $€ / \mathrm{kWh}$, in real prices, for the candidate technology $k, C_{C j}$ is the capital cost function in $€, C_{F j}$ is the fuel cost function in $€, C_{O M F j}$ is the fixed O\&M cost function in $€, \mathrm{C}_{\mathrm{OMV}}$ is the variable O\&M cost function in $€, P_{j}$ is the total electricity production in $\mathrm{kWh}$, $j=1,2, \ldots, N$ is the periods (e.g., years) of installation and operation of the power generation technology, and $i$ is the discount rate. The least cost solution is calculated as follows:

$$
\text { least cost solution }=\min \left[\frac{\partial c}{\partial k}\right] \text {. }
$$

During the simulations procedure, the following financial feasibility indicators based on the individual case examined may be calculated: (a) electricity unit cost or benefit before tax (in $€ / \mathrm{kWh}$ ), (b) after-tax cash flow (in $€$ ), (c) after tax NPV (net present value: the value of all future cash flows,

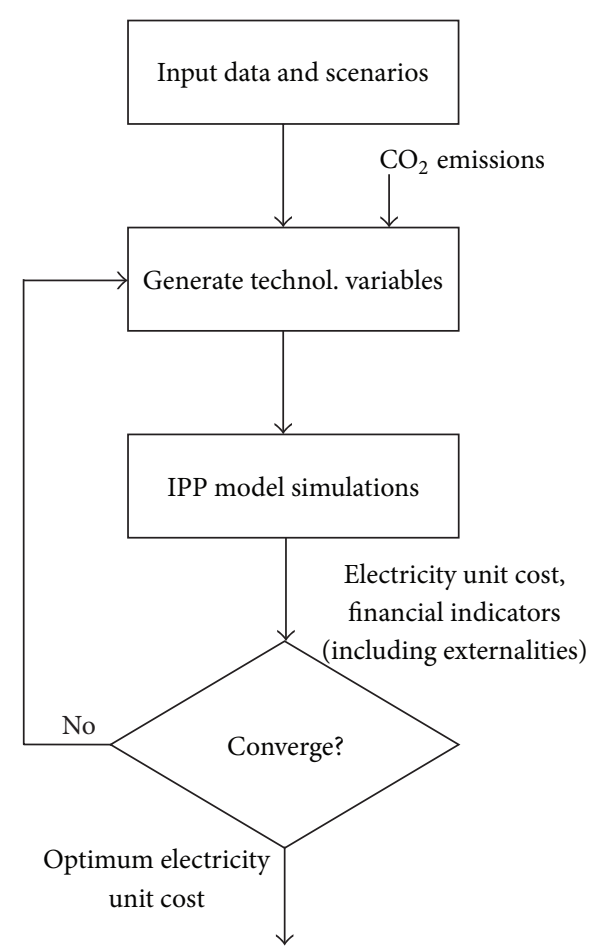

FIGURE 2: Flowchart of the IPP optimization model.

discounted at the discount rate, in today's currency), (d) aftertax IRR (internal rate of return: the discount rate that causes the NPV of the project to be zero and is calculated using the after tax-cash flows; note that the IRR is undefined in certain cases, notably if the project yields immediate positive cash flow in year zero), and (e) after-tax PBP (payback period: the number of years it takes for the cash flow, excluding debt payments, to equal the total investment which is equal to the sum of debt and equity).

\section{Input Data and Scenarios}

For the purposes of the comparative optimization analysis, the electricity generation technologies to be investigated are a 420 MWe CCGT natural gas technology (with a fuel net calorific value of $46.3 \mathrm{GJ} / \mathrm{t}$ and a fuel carbon content of $76.24 \%$ ) at a $75 \%$ capacity factor, a $50 \mathrm{MWe}$ PT-CSP technology, and a $17 \mathrm{MWe}$ ST-CSP technology. Both CSP technologies are not integrated with thermal storage capability.

Regarding the CCGT technology analysis, two cases were examined, namely, the base case and the alternative case, each using different natural gas prices. Specifically, the natural gas price projections used in the analysis for the base and the alternative case are shown in Figure 3. Essentially, in the alternative case, the price of natural gas is reduced by $40 \%$ compared to the base case in each year. Moreover, in order to account for the unpredictability of the electricity generation when the CCGT technology is integrated with the MACC cooling system, since such a system is not yet commercialized and its actual behavior is not as yet well predicted in existing 


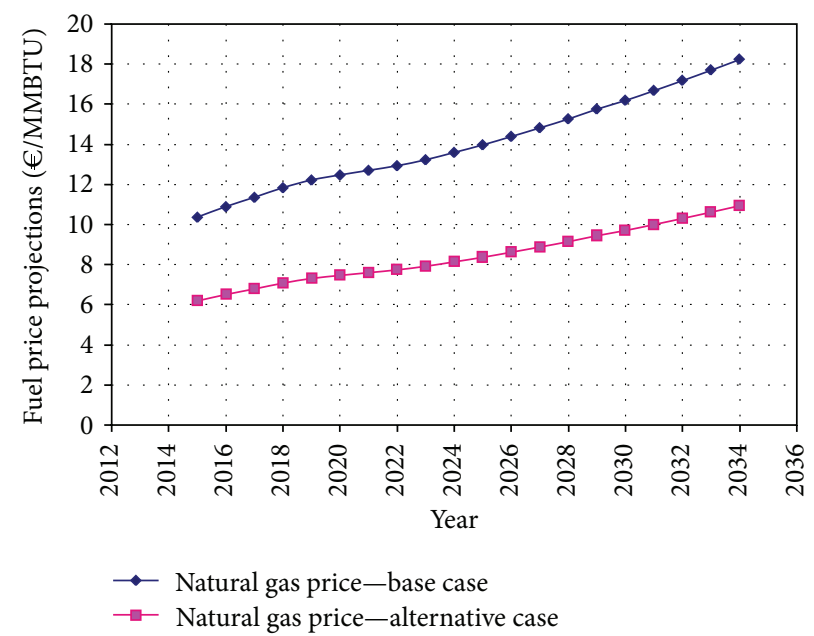

FIGURE 3: Annual price projections of natural gas (nominal values).

software design tools, the efficiency of the CCGT technology system was varied at 56\% (low), 57\% (medium), and 58\% (high) in both the base and alternative cases.

The input data and scenarios used in the CCGT technology comparative optimization analysis are shown in Table 1.

Regarding the CSP technologies, since the MACC system would be integrated as the main cooling system in a $50 \mathrm{MWe}$ PT-CSP and a 17 MWe ST-CSP technology systems, an annual direct normal irradiance (DNI) factor of $2000 \mathrm{kWh} / \mathrm{m}^{2}$ typical of Larnaca, Cyprus, which is considered as a normal DNI level for the Mediterranean region, is used for the analysis. However, in order to study the effect of varying DNI levels on the competitiveness of the MACC system, two additional DNI levels were also studied, namely, a high DNI level of $2500 \mathrm{kWh} / \mathrm{m}^{2}$ typical of Luxor, Egypt, and a low DNI level of $1500 \mathrm{kWh} / \mathrm{m}^{2}$ typical of Athens, Greece. The input data and scenarios used in the CSP technologies comparative optimization analysis are shown in Table 2 for the PT-CSP technology and in Table 3 for the ST-CSP technology. Regarding the analysis of the PT-CSP and STCSP technologies when integrated with the MACC system, the overall CSP technology system efficiency was varied, for reasons already explained above. Specifically, for the PTCSP technology, the efficiency was varied between $12.5 \%$ (low), $13.5 \%$ (medium), and $14.5 \%$ (high), while for the STCSP technology, it was varied between $14.5 \%$ (low), $15.5 \%$ (medium), and $16.5 \%$ (high). The input data regarding the ST-CSP technology was based on the PS10 and PS20 solar tower CSP plants that are currently in operation in Spain, since the Gemasolar solar tower CSP plant is integrated with thermal storage capability through an innovative $24 \mathrm{~h}$ storage technology with molten salt [16].

Throughout the simulations, a typical discount rate of $6 \%$ is assumed. In order to calculate the after-tax cash flows and after-tax financial indicators, a single $10 \%$ income tax rate is assumed that is constant throughout the project life and applied to net income. Also, the economic life of the CCGT and the two CSP systems is assumed at 20 years. The

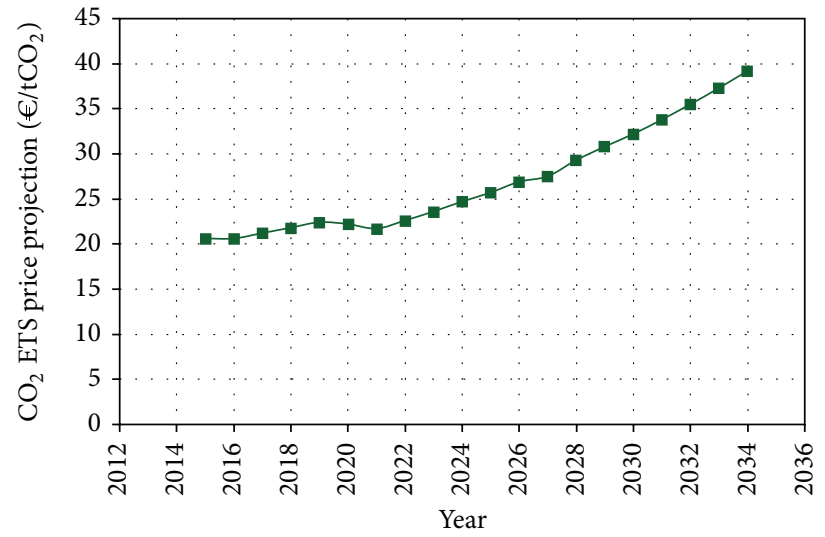

FIGURE 4: Annual price projections of $\mathrm{CO}_{2}$ ETS price (real values).

simulations consider a $\mathrm{CO}_{2}$ emission trading scheme (ETS) price projection, as shown in Figure 4, to account for the environmental cost of the CCGT technology. The simulations do not consider any feed-in tariff or other subsidy scheme for the application of CSP technologies.

\section{Results and Discussion}

In this section, the results of the comparative optimization analysis are discussed. The electricity unit cost of each scenario investigated is used as the sole criterion in order to assess the competitiveness of the MACC system.

4.1. CCGT Technology Electricity Unit Cost Comparison. The results concerning the electricity unit cost of the $420 \mathrm{MWe}$ CCGT technology when integrated with a conventional water-cooled condenser, dry-cooled condenser, and with the innovative MACC system are shown in Figure 5. The comparison of each scenario shows that the electricity unit cost of the CCGT technology integrated with the MACC 
TABLE 1: Input data and scenarios for CCGT technology comparative analysis.

\begin{tabular}{|c|c|c|c|c|c|}
\hline Scenario & $\begin{array}{l}\text { Capacity } \\
\text { MWe }\end{array}$ & $\begin{array}{c}\text { Specific capital cost } \\
€ / \mathrm{kW}\end{array}$ & $\begin{array}{c}\text { Efficiency } \\
\%\end{array}$ & $\begin{array}{l}\text { Fixed } \mathrm{O} \text { and } \mathrm{M} \\
€ / \mathrm{kW} / \mathrm{month}\end{array}$ & $\begin{array}{c}\text { Variable } \mathrm{O} \text { and } \mathrm{M} \\
€ / \mathrm{MWh}\end{array}$ \\
\hline CCGT, water cooling, base case & 420 & 665 & 57.20 & 2.34 & 1.62 \\
\hline CCGT, dry cooling, base case & 420 & 737 & 56.30 & 2.34 & 1.62 \\
\hline CCGT, MACC cooling, base case, $56 \%$ efficiency & 420 & 666 & 56.00 & 2.37 & 1.62 \\
\hline CCGT, MACC cooling, base case, $57 \%$ efficiency & 420 & 666 & 57.00 & 2.37 & 1.62 \\
\hline CCGT, MACC cooling, base case, $58 \%$ efficiency & 420 & 666 & 58.00 & 2.37 & 1.62 \\
\hline CCGT, water cooling, alternative case & 420 & 665 & 57.20 & 2.34 & 1.62 \\
\hline CCGT, dry cooling, alternative case & 420 & 737 & 56.30 & 2.34 & 1.62 \\
\hline CCGT, MACC cooling, alternative case, $56 \%$ efficiency & 420 & 666 & 56.00 & 2.37 & 1.62 \\
\hline CCGT, MACC cooling, alternative case, $57 \%$ efficiency & 420 & 666 & 57.00 & 2.37 & 1.62 \\
\hline CCGT, MACC cooling, alternative case, $58 \%$ efficiency & 420 & 666 & 58.00 & 2.37 & 1.62 \\
\hline
\end{tabular}

TABLE 2: Input data and scenarios for PT-CSP technology comparative analysis.

\begin{tabular}{|c|c|c|c|c|c|c|}
\hline \multirow[t]{2}{*}{ Scenario } & \multirow{2}{*}{$\begin{array}{c}\text { Capacity } \\
\text { MWe }\end{array}$} & \multirow{2}{*}{$\begin{array}{c}\text { Specific capital cost } \\
€ / \mathrm{kW}\end{array}$} & \multirow{2}{*}{$\begin{array}{c}\text { Efficiency } \\
\%\end{array}$} & \multirow{2}{*}{$\begin{array}{l}\text { Fixed } \mathrm{O} \text { and } \mathrm{M} \\
€ / \mathrm{kW} / \text { month }\end{array}$} & \multirow{2}{*}{$\begin{array}{c}\text { Variable } \mathrm{O} \text { and } \mathrm{M} \\
\qquad € / \mathrm{MWh}\end{array}$} & \multirow{2}{*}{$\begin{array}{c}\text { Capacity } \\
\text { factor } \\
\%\end{array}$} \\
\hline & & & & & & \\
\hline PT-CSP, water cooling, high DNI & 50 & 4943 & 14.00 & 9.90 & 2.48 & 29.10 \\
\hline PT-CSP, water cooling, normal DNI & 50 & 4943 & 14.00 & 9.90 & 2.48 & 22.50 \\
\hline PT-CSP, water cooling, low DNI & 50 & 4943 & 14.00 & 9.90 & 2.48 & 17.50 \\
\hline PT-CSP, dry cooling, high DNI & 50 & 5059 & 12.70 & 9.90 & 2.48 & 27.30 \\
\hline PT-CSP, dry cooling, normal DNI & 50 & 5059 & 12.70 & 9.90 & 2.48 & 21.50 \\
\hline PT-CSP, dry cooling, low DNI & 50 & 5059 & 12.70 & 9.90 & 2.48 & 16.60 \\
\hline $\begin{array}{l}\text { PT-CSP, MACC cooling, high DNI, } 12.5 \% \\
\text { efficiency }\end{array}$ & 50 & 4970 & 12.50 & 9.93 & 2.48 & 25.98 \\
\hline $\begin{array}{l}\text { PT-CSP, MACC cooling, high DNI, 13.5\% } \\
\text { efficiency }\end{array}$ & 50 & 4970 & 13.50 & 9.93 & 2.48 & 28.06 \\
\hline $\begin{array}{l}\text { PT-CSP, MACC cooling, high DNI, } 14.5 \% \\
\text { efficiency }\end{array}$ & 50 & 4970 & 14.50 & 9.93 & 2.48 & 30.14 \\
\hline $\begin{array}{l}\text { PT-CSP, MACC cooling, normal DNI, } 12.5 \% \\
\text { efficiency }\end{array}$ & 50 & 4970 & 12.50 & 9.93 & 2.48 & 20.09 \\
\hline $\begin{array}{l}\text { PT-CSP, MACC cooling, normal DNI, 13.5\% } \\
\text { efficiency }\end{array}$ & 50 & 4970 & 13.50 & 9.93 & 2.48 & 21.70 \\
\hline $\begin{array}{l}\text { PT-CSP, MACC cooling, normal DNI, } 14.5 \% \\
\text { efficiency }\end{array}$ & 50 & 4970 & 14.50 & 9.93 & 2.48 & 23.30 \\
\hline $\begin{array}{l}\text { PT-CSP, MACC cooling, low DNI, } 12.5 \% \\
\text { efficiency }\end{array}$ & 50 & 4970 & 12.50 & 9.93 & 2.48 & 15.63 \\
\hline $\begin{array}{l}\text { PT-CSP, MACC cooling, low DNI, 13.5\% } \\
\text { efficiency }\end{array}$ & 50 & 4970 & 13.50 & 9.93 & 2.48 & 16.88 \\
\hline $\begin{array}{l}\text { PT-CSP, MACC cooling, low DNI, 14.5\% } \\
\text { efficiency }\end{array}$ & 50 & 4970 & 14.50 & 9.93 & 2.48 & 18.13 \\
\hline
\end{tabular}

system is in all cases lower than that of the same technology integrated with the dry-cooled condenser. This means that the MACC system can be considered as a cost-competitive alternative to the conventional dry-cooled condenser, to be integrated with the CCGT technology.

Specifically, in the base case, the results show that when the efficiency of the CCGT technology integrated with the MACC system is $56 \%$ or $57 \%$, its electricity unit cost is lower than that of the same technology integrated with the dry-cooled condenser but remains slightly higher than that of the CCGT technology integrated with the watercooled condenser. For example, the electricity unit cost of the CCGT technology with the MACC system at a $56 \%$ efficiency is $10.59 € \mathrm{c} / \mathrm{kWh}$, while with the water-cooled condenser is $10.39 € \mathrm{c} / \mathrm{kWh}$, and with the dry-cooled condenser it is $10.63 € \mathrm{c} / \mathrm{kWh}$. However, as the efficiency of the CCGT technology with the MACC system increases to $58 \%$, the respective electricity unit cost decreases even further. In fact, at $58 \%$ efficiency, the CCGT technology integrated with the MACC system is more economical than both the CCGT 
TABLE 3: Input data and scenarios for ST-CSP technology comparative analysis.

\begin{tabular}{|c|c|c|c|c|c|c|}
\hline \multirow[t]{2}{*}{ Scenario } & \multirow{2}{*}{$\begin{array}{c}\text { Capacity } \\
\text { MWe }\end{array}$} & \multirow{2}{*}{$\begin{array}{c}\text { Specific capital cost } \\
€ / \mathrm{kW}\end{array}$} & \multirow{2}{*}{$\begin{array}{c}\text { Efficiency } \\
\% \\
\end{array}$} & \multirow{2}{*}{$\begin{array}{l}\text { Fixed } \mathrm{O} \text { and } \mathrm{M} \\
€ / \mathrm{kW} / \mathrm{month}\end{array}$} & \multirow{2}{*}{$\begin{array}{l}\text { Variable } \mathrm{O} \text { and } \mathrm{M} \\
\qquad € / \mathrm{MWh}\end{array}$} & \multirow{2}{*}{$\begin{array}{c}\text { Capacity } \\
\text { factor } \\
\%\end{array}$} \\
\hline & & & & & & \\
\hline ST-CSP, water cooling, high DNI & 17 & 6471 & 16.08 & 9.20 & 2.48 & 22.40 \\
\hline ST-CSP, water cooling, normal DNI & 17 & 6471 & 16.08 & 9.20 & 2.48 & 17.30 \\
\hline ST CSP, water cooling, low DNI & 17 & 6471 & 16.08 & 9.20 & 2.48 & 13.30 \\
\hline ST-CSP, dry cooling, high DNI & 17 & 6587 & 14.86 & 9.20 & 2.48 & 21.20 \\
\hline ST-CSP, dry cooling, normal DNI & 17 & 6587 & 14.86 & 9.20 & 2.48 & 16.60 \\
\hline ST-CSP, dry cooling, low DNI & 17 & 6587 & 14.86 & 9.20 & 2.48 & 12.70 \\
\hline $\begin{array}{l}\text { ST-CSP, MACC cooling, high DNI, 14.5\% } \\
\text { efficiency }\end{array}$ & 17 & 6482 & 14.50 & 9.23 & 2.48 & 20.20 \\
\hline $\begin{array}{l}\text { ST-CSP, MACC cooling, high DNI, 15.5\% } \\
\text { efficiency }\end{array}$ & 17 & 6482 & 15.50 & 9.23 & 2.48 & 21.59 \\
\hline $\begin{array}{l}\text { ST-CSP, MACC cooling, high DNI, 16.5\% } \\
\text { efficiency }\end{array}$ & 17 & 6482 & 16.50 & 9.23 & 2.48 & 22.99 \\
\hline $\begin{array}{l}\text { ST-CSP, MACC cooling, normal DNI, 14.5\% } \\
\text { efficiency }\end{array}$ & 17 & 6482 & 14.50 & 9.23 & 2.48 & 15.60 \\
\hline $\begin{array}{l}\text { ST-CSP, MACC cooling, normal DNI, 15.5\% } \\
\text { efficiency }\end{array}$ & 17 & 6482 & 15.50 & 9.23 & 2.48 & 16.68 \\
\hline $\begin{array}{l}\text { ST-CSP, MACC cooling, normal DNI, 16.5\% } \\
\text { efficiency }\end{array}$ & 17 & 6482 & 16.50 & 9.23 & 2.48 & 17.75 \\
\hline $\begin{array}{l}\text { ST-CSP, MACC cooling, low DNI, } 14.5 \% \\
\text { efficiency }\end{array}$ & 17 & 6482 & 14.50 & 9.23 & 2.48 & 11.99 \\
\hline $\begin{array}{l}\text { ST-CSP, MACC cooling, low DNI, 15.5\% } \\
\text { efficiency }\end{array}$ & 17 & 6482 & 15.50 & 9.23 & 2.48 & 12.82 \\
\hline $\begin{array}{l}\text { ST-CSP, MACC cooling, low DNI, } 16.5 \% \\
\text { efficiency }\end{array}$ & 17 & 6482 & 16.50 & 9.23 & 2.48 & 13.65 \\
\hline
\end{tabular}

water-cooled and the dry-cooled technologies, showing that the MACC system integrated in a CCGT technology can become a cost-competitive alternative to the conventional water-cooled condenser as well.

The results in the CCGT alternative case provide the same observations as above, in that the innovative MACC system is a cost-competitive alternative to a conventional dry-cooled condenser and that in higher efficiencies it can even become cost competitive to the conventional water-cooled condenser. Clearly, the electricity unit cost range in the alternative case (which is between $7.13 € \mathrm{c} / \mathrm{kWh}$ and $7.39 € \mathrm{c} / \mathrm{kWh}$ ) is lower than that of the base case due to the lower natural gas price projections considered.

\subsection{PT-CSP Technology Electricity Unit Cost Comparison.} The results concerning the electricity unit cost of the $50 \mathrm{MWe}$ PT-CSP technology when integrated with a conventional water-cooled condenser, dry-cooled condenser and with the innovative MACC system are shown in Figure 6. The comparison of each scenario shows that the competitiveness of the MACC system, compared to the conventional water-cooled and dry-cooled condensers, depends heavily on the PT-CSP technology efficiency level. This observation applies to all DNI cases examined, that is, low, normal, and high. Specifically, at the low $12.5 \%$ efficiency level, the PTCSP technology with the MACC system has an electricity unit cost higher than both of the PT-CSP technologies with water-cooled and dry-cooled condensers. Therefore, at such efficiency level, the MACC system is not considered a competitive condensing technology to be integrated in a PT-CSP technology. However, at the higher efficiencies examined, the MACC system offers more competitive results. At the medium-efficiency level, the MACC system is cost competitive only to the dry-cooled condenser, while at the high-efficiency level, the MACC system is cost competitive to both water-cooled and dry-cooled condensers.

For example, in the high DNI case, at $12.5 \%$ efficiency, the electricity unit cost of the PT-CSP technology integrated with the MACC system is $24.52 € \mathrm{c} / \mathrm{kWh}$, while with the water-cooled condenser is $21.81 € \mathrm{c} / \mathrm{kWh}$, and with the drycooled condenser is $23.70 € \mathrm{c} / \mathrm{kWh}$. However, at the high $14.5 \%$ efficiency, the PT-CSP technology integrated with the MACC system has lower electricity unit cost than both of the PT-CSP technologies integrated with water-cooled and dry-cooled condensers. Specifically, the electricity unit cost of the PT-CSP technology integrated with the MACC system is $21.17 € \mathrm{c} / \mathrm{kWh}$, lower than both the $21.81 € \mathrm{c} / \mathrm{kWh}$ of the watercooled and the $23.70 € \mathrm{c} / \mathrm{kWh}$ of the dry-cooled condensers. Therefore, at such efficiency level, the MACC system can be considered as a competitive condensing technology to be integrated in a PT-CSP technology as an alternative to both water-cooled and dry-cooled condensers. 


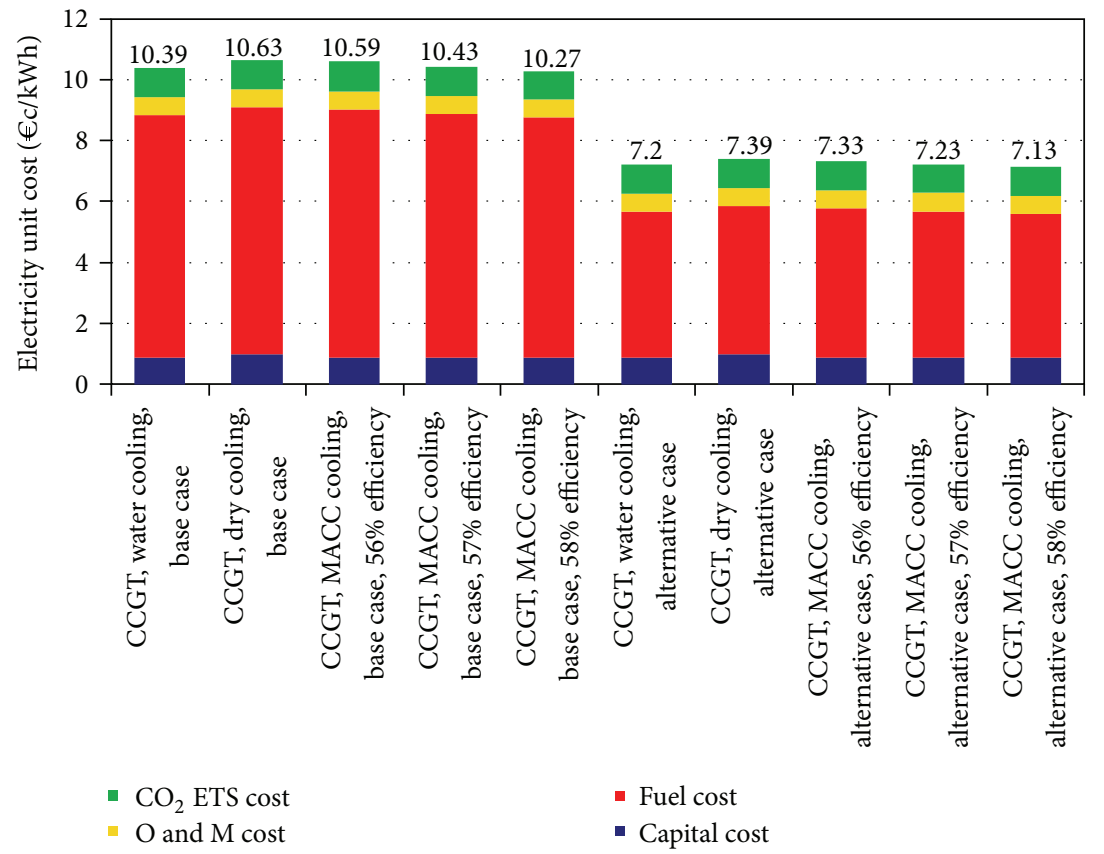

FIGURE 5: MACC system competitiveness integrated in CCGT technology.

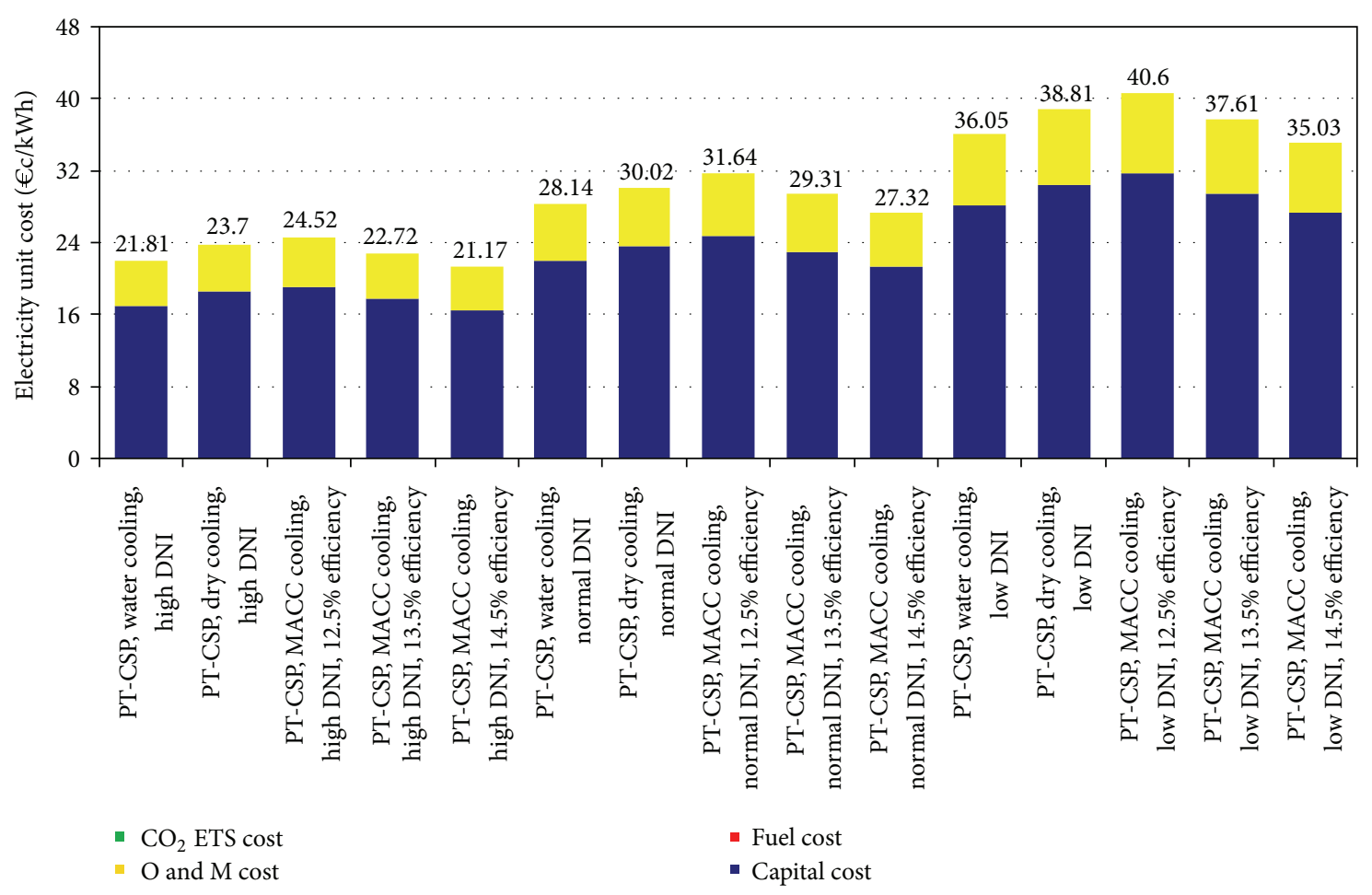

FIGURE 6: MACC system competitiveness integrated in PT-CSP technology.

4.3. ST-CSP Technology Electricity Unit Cost Comparison. The results concerning the electricity unit cost of the $17 \mathrm{MWe}$ ST-CSP technology when integrated with a conventional water-cooled condenser, dry-cooled condenser, and with the innovative MACC system are shown in Figure 7. The comparison of each scenario shows that, as in the case of the PT-CSP technology, the competitiveness of the MACC system, compared to the conventional water-cooled and drycooled condensers, depends heavily on the ST-CSP technology efficiency level. This observation applies to all DNI cases examined, that is, low, normal, and high. Specifically, at the low $14.5 \%$ efficiency level, the ST-CSP technology integrated 


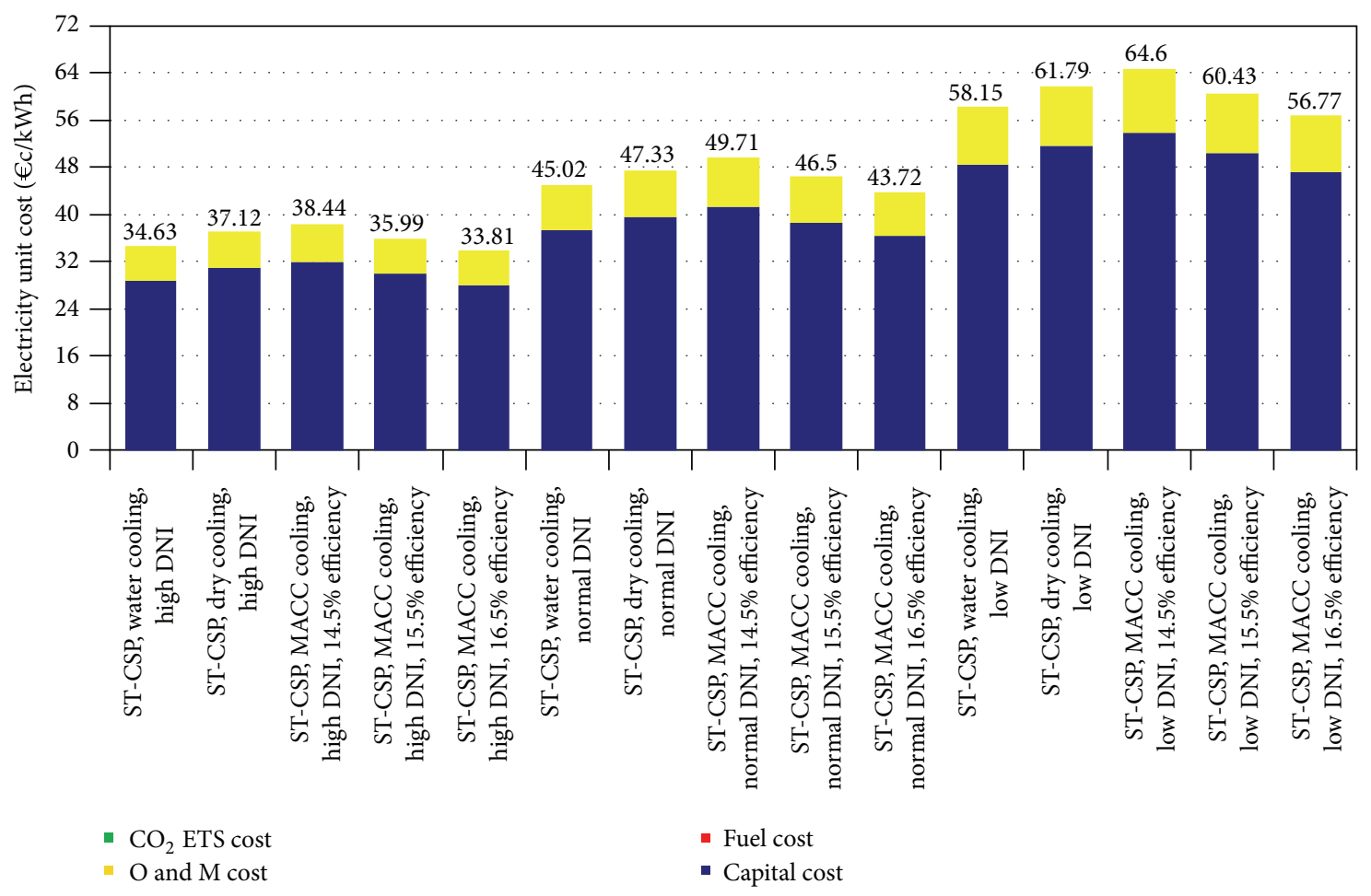

FIGURE 7: MACC system competitiveness integrated in ST-CSP technology.

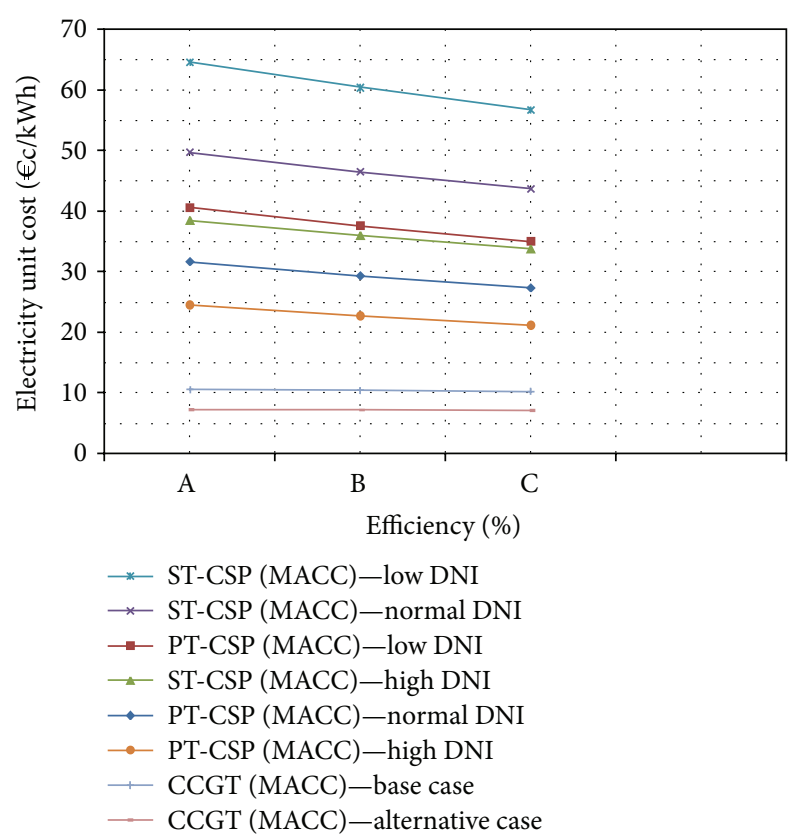

FIGURE 8: Comparison of electricity generation technologies integrated with the MACC system.

with the MACC system has an electricity unit cost higher than both of the ST-CSP technologies with water-cooled and dry-cooled condensers. Therefore, at such efficiency level, the MACC system is not considered a competitive condensing technology to be integrated in a ST-CSP technology. However, at the higher efficiencies examined, the MACC system offers more competitive results. At the medium-efficiency level, the MACC system is cost competitive only to the dry-cooled condenser, while at the high-efficiency level, the MACC system is cost competitive to both water-cooled and dry-cooled condensers.

For example, in the high DNI case, at $14.5 \%$ efficiency, the electricity unit cost of the ST-CSP technology with the MACC system is $38.44 € \mathrm{c} / \mathrm{kWh}$, while with the watercooled condenser is $34.63 € \mathrm{c} / \mathrm{kWh}$, and with the dry-cooled condenser is $37.12 € \mathrm{c} / \mathrm{kWh}$. However, at the high $16.5 \%$ efficiency, the ST-CSP technology integrated with the MACC system has lower electricity unit cost than both the ST-CSP technologies integrated with water-cooled and dry-cooled condensers. Specifically, the electricity unit cost of the STCSP technology with the MACC system is $33.81 € \mathrm{c} / \mathrm{kWh}$, lower than both the $34.63 € \mathrm{c} / \mathrm{kWh}$ of the water-cooled and the $37.12 € \mathrm{c} / \mathrm{kWh}$ of the dry-cooled condensers. Therefore, at such efficiency level, the MACC system can be considered as a competitive condensing technology to be integrated in a STCSP technology as an alternative to both water-cooled and dry-cooled condensers.

4.4. Comparison of Technologies Integrated with the MACC System. Finally, an overall comparison of the competitiveness of each of the three types of electricity generation technologies examined, that is, CCGT, PT-CSP, and ST-CSP, when integrated with the MACC system, is provided in Figure 8. In the $x$-axis, the labels $\mathrm{A}, \mathrm{B}$, and $\mathrm{C}$ refer, respectively, to 
the low-, medium-, and high-efficiency levels in the efficiency range examined individually for each generation technology. For example, in the case of the PT-CSP technology, A would refer to $12.5 \%, \mathrm{~B}$ to $13.5 \%$, and $\mathrm{C}$ to $14.5 \%$ efficiency. The comparison shows that the CCGT technology integrated with the MACC system is the most competitive of the three types of technologies, exhibiting the lowest electricity unit costs. Depending on the efficiency, the electricity unit cost ranges around $7 € \mathrm{c} / \mathrm{kWh}$ in the alternative case and $10 € \mathrm{c} / \mathrm{kWh}$ in the base case.

The electricity unit cost of the CSP technologies integrated with the MACC system depends on the efficiency of each technology and the DNI level. Comparison-wise, the PT-CSP technology generally exhibits lower electricity unit costs than the ST-CSP technology, ranging from around $25 € \mathrm{c} / \mathrm{kWh}$ to $40 € \mathrm{c} / \mathrm{kWh}$ in the low-efficiency case (depending on the DNI level) and from $20 € \mathrm{c} / \mathrm{kWh}$ to $35 € \mathrm{c} / \mathrm{kWh}$ in the high-efficiency case, while the ST-CSP technology has from around $38 € \mathrm{c} / \mathrm{kWh}$ to $65 € \mathrm{c} / \mathrm{kWh}$ in the low-efficiency case and from $34 € \mathrm{c} / \mathrm{kWh}$ to $57 € \mathrm{c} / \mathrm{kWh}$ in the high-efficiency case. Importantly though, the ST-CSP technology at high DNI level has lower electricity unit costs across all efficiency levels than the PT-CSP technology at low DNI level.

In terms of classification, the three most competitive scenarios of CSP technology integrated with the MACC system are the PT-CSP at high DNI, followed by the PT-CSP at normal DNI and the ST-CSP at high DNI level.

\section{Conclusions}

In this work, a technical and economic comparative optimization assessment is carried out using the IPP v2.1 software package in order to identify the optimum MACC system competitiveness in relation to conventional dry-cooled or water-cooled condensers. Specifically, the techno-economic performance of the CCGT technology, the parabolic trough CSP (PT-CSP) technology, and the solar tower CSP (ST-CSP) technology are compared when all are integrated (a) with a MACC condenser of an optimum tube geometry and size, (b) with a conventional water-cooled condenser, and (c) with a conventional dry-cooled condenser.

Based on the input data and assumptions made, the comparative optimization analysis shows that, in the case of the CCGT technology, the MACC system is a costcompetitive technology to the conventional dry-cooled condenser. In addition, at higher efficiencies, the MACC system can even become cost competitive to the conventional water-cooled condenser. In the case of the PT-CSP and ST-CSP technologies, the results show that, irrespective of the location's DNI level, the competitiveness of the MACC system, compared to the conventional water-cooled and drycooled condensers, depends heavily on the efficiency level. At low CSP technology efficiency levels, the MACC system is not considered a competitive condensing technology to either the conventional water- or dry-cooled condensers. However, at higher efficiency levels, the MACC system begins to become cost competitive first to the dry-cooled condensers and then, at even higher efficiency levels, to the water-cooled condensers as well.
Finally regarding the competitiveness of each of the three types of electricity generation technologies examined (i.e., CCGT, PT-CSP, and ST-CSP), when integrated with a MACC system, the most cost-competitive technology is the CCGT technology (alternative and base cases). Concerning the CSP technologies, the three most cost-competitive scenarios are the PT-CSP at high DNI, followed by the PT-CSP at normal DNI, and the ST-CSP at high DNI level.

\section{Acknowledgment}

This work was supported in part by the Seventh Framework Program of Research and Development of the European Union, Contract no. FP7-ENERGY-2010-1/256797.

\section{References}

[1] W. Micheletti and J. Burns, "Emerging issues and needs in power plant cooling systems," in Proceedings of the Water issues in Fossil Energy Workshop, 2002.

[2] U.S. Department of Energy, "Concentrating solar power commercial application study: reducing water consumption of concentrating solar power electricity generation," Report to Congress, 2009.

[3] M. A. Valencia, "Solar power scale-up in the MENA: resolving the associated water use challenges," The Environment and the Middle East, vol. 1, pp. 13-19, 2011.

[4] B. Kelly, "Nexant parabolic trough solar power plant systems analysis," Tech. Rep. NREL/SR-550-40163, National Renewable Energy Laboratory, 2006.

[5] P. Liu, H. Duan, and W. Zhao, "Numerical investigation of hot air recirculation of air-cooled condensers at a large power plant," Applied Thermal Engineering, vol. 29, no. 10, pp. 1927-1934, 2009.

[6] A. Poullikkas, I. Hadjipaschalis, and G. Kourtis, "Review of the existing and emerging water cooled and air cooled condensers suitable for CSP plants," Tech. Rep. TR/2011/ET/2, Electricity Authority of Cyprus, 2011.

[7] (The development and verification of a novel modular air cooled condenser for enhanced concentrated solar power generation-MACCSol, EC contract no. 256797), http://www .drycooledcsp.eu/.

[8] P. Viebahn, Y. Lechon, and F. Trieb, “The potential role of concentrated solar power (CSP) in Africa and Europe-A dynamic assessment of technology development, cost development and life cycle inventories until 2050," Energy Policy, vol. 39, no. 8, pp. 4420-4430, 2011.

[9] (Euromed, The Mediterranean Solar Plan), http://www.enpiinfo.eu/.

[10] F. Tieb, "TRANS CSP-Trans-Mediterranean interconnection for Concentrating solar power," Tech. Rep. for the German Ministry of the Environment, Nature Conservation and Nuclear Safety, DLR, (German Aerospace Centre), 2006.

[11] A. Poullikkas, I. Hadjipaschalis, and G. Kourtis, "Lifetime cost-benefit analysis of prototype MACC system," Tech. Rep. TR/2011/ET1/11, Electricity Authority of Cyprus, 2011.

[12] A. Poullikkas, I. Hadjipaschalis, and G. Kourtis, "Lifetime costbenefit analysis of MACC system with geometry B," Tech. Rep. TR/2011/ET1/12, Electricity Authority of Cyprus, 2011.

[13] A. Poullikkas, R. Grimes, E. Walsh, I. Hadjipaschalis, and G. Kourtis, "Optimization analysis of innovative modular aircooled condensers for CSP plants," in Proceedings of the 8th Med Power, Sardinia, Italy, October 2012. 
[14] A. Poullikkas, I. Hadjipaschalis, and G. Kourtis, "Parametric cost-benefit techno-economic analysis for MACC system optimum geometry and operating conditions," Tech. Rep. TR/2012/ET1/6, Electricity Authority of Cyprus, 2012.

[15] A. Poullikkas, "A decouple optimization method for power technology selection in competitive markets," Energy Sources B, vol. 4, no. 2, pp. 199-211, 2009.

[16] A. Poullikkas, "Economic analysis of power generation from parabolic trough solar thermal plants for the Mediterranean region-A case study for the island of Cyprus," Renewable and Sustainable Energy Reviews, vol. 13, no. 9, pp. 2474-2484, 2009. 

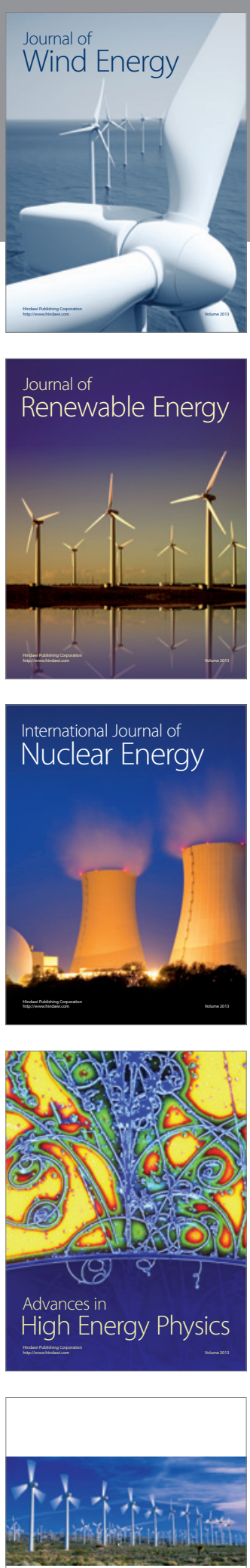

ISRN

Renewable Energy
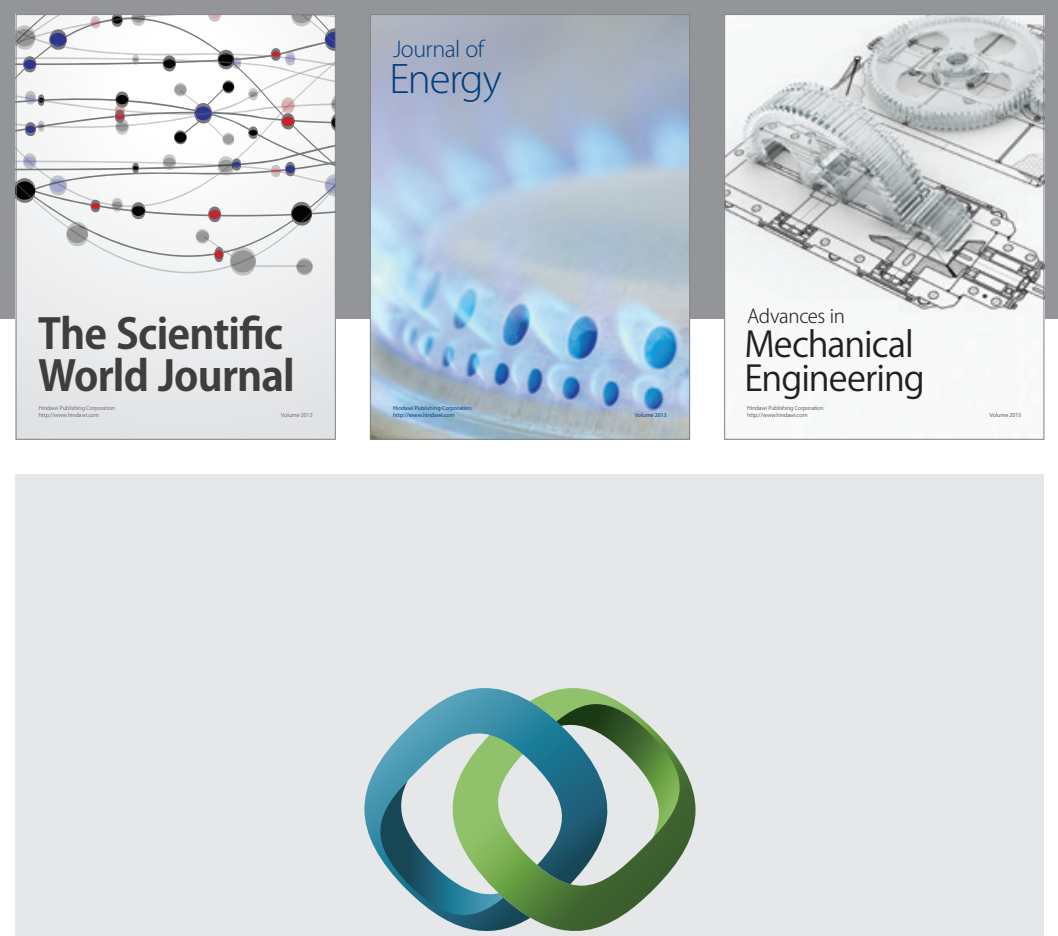

\section{Hindawi}

Submit your manuscripts at http://www.hindawi.com
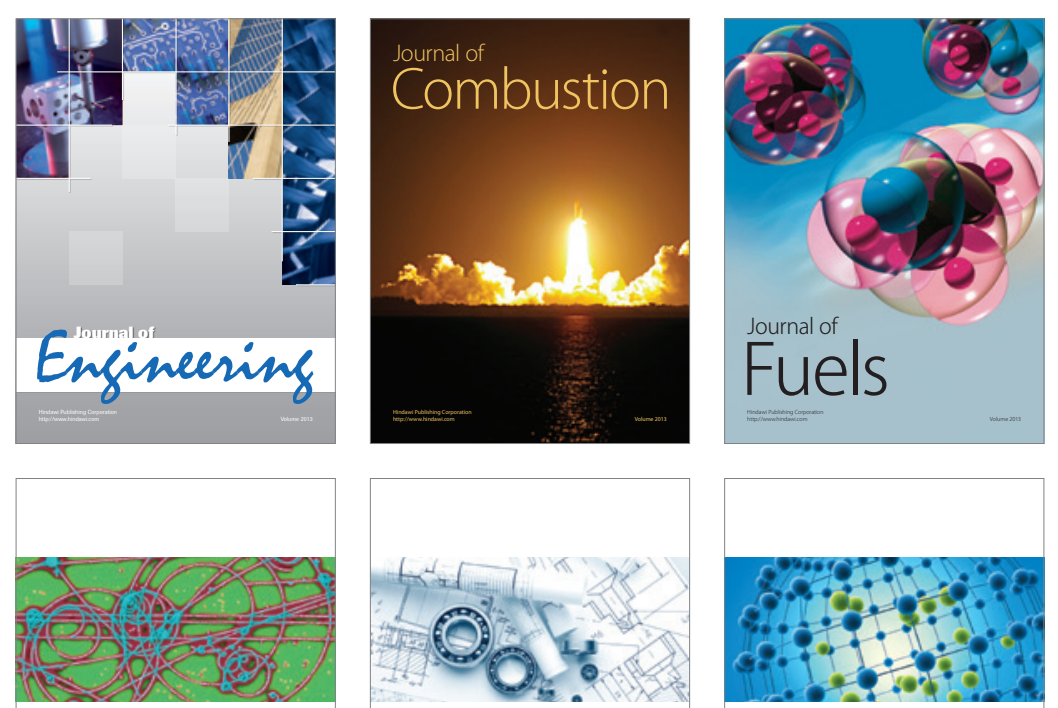

ISRN

High Energy Physics

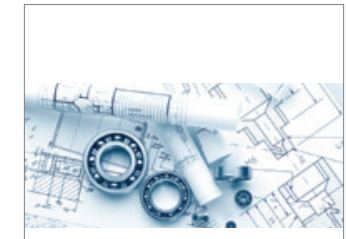

ISRN

Mechanical

Engineering

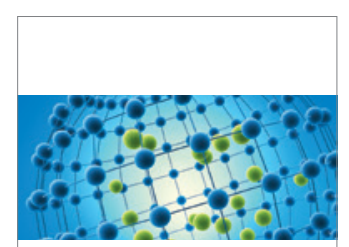

ISRN

Chemical

Engineering
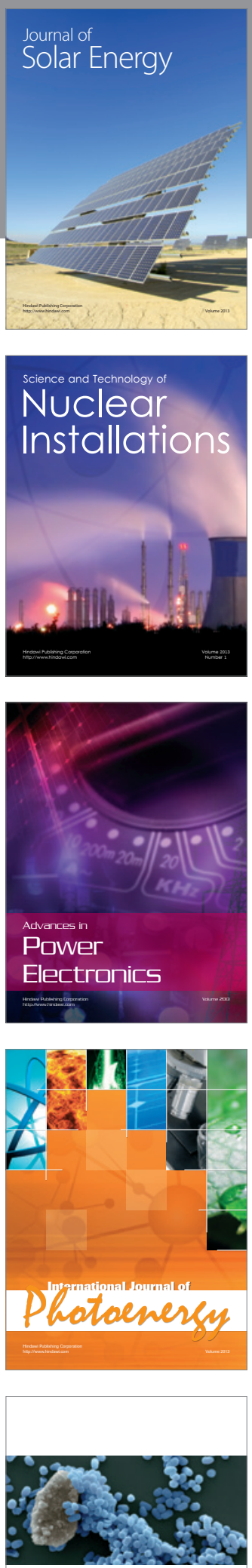

ISRN

Biotechnology 

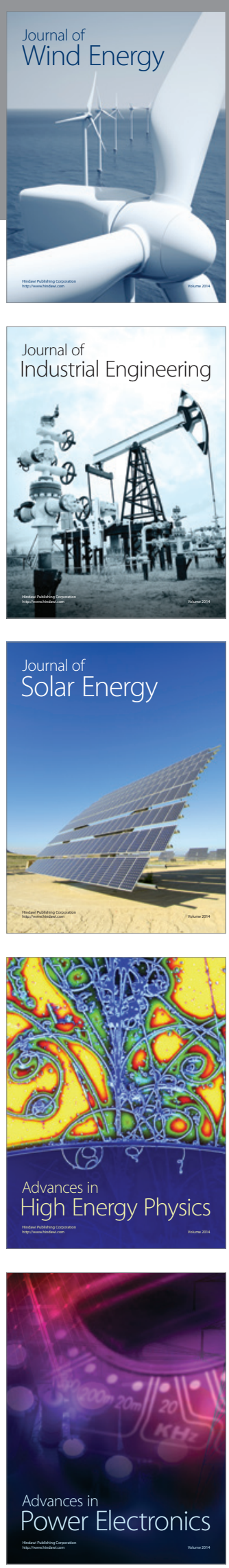
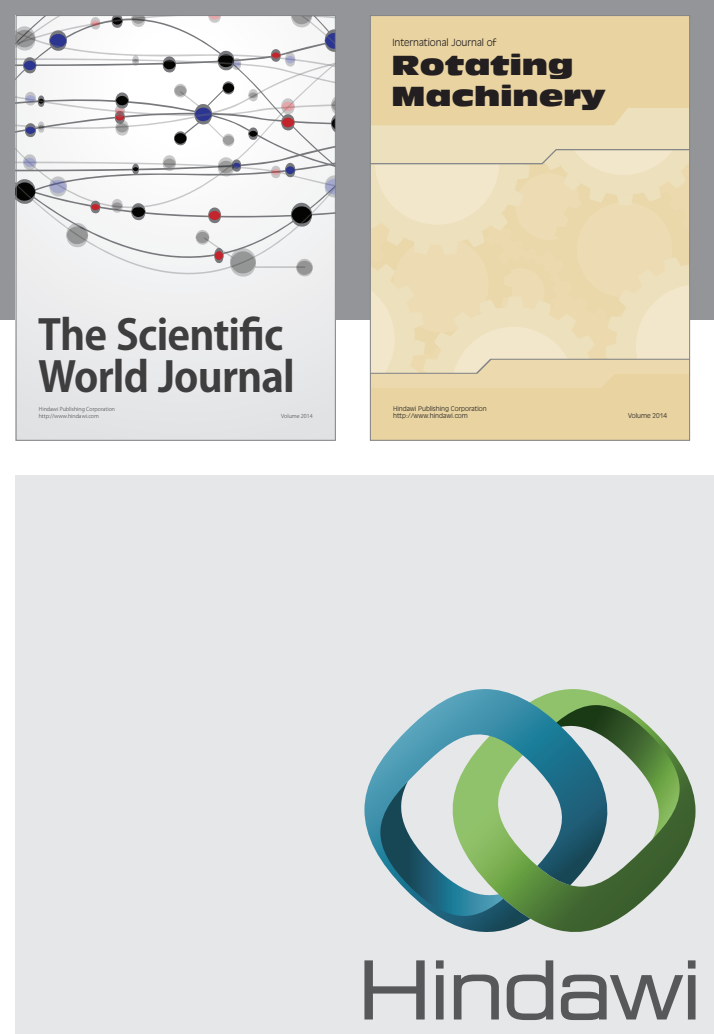

Submit your manuscripts at

http://www.hindawi.com
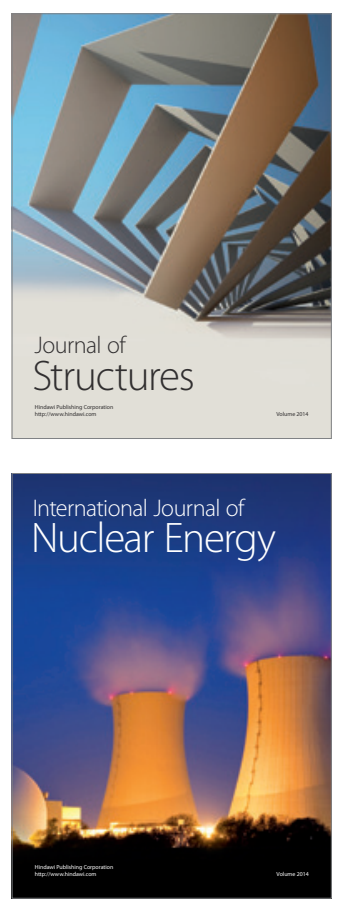
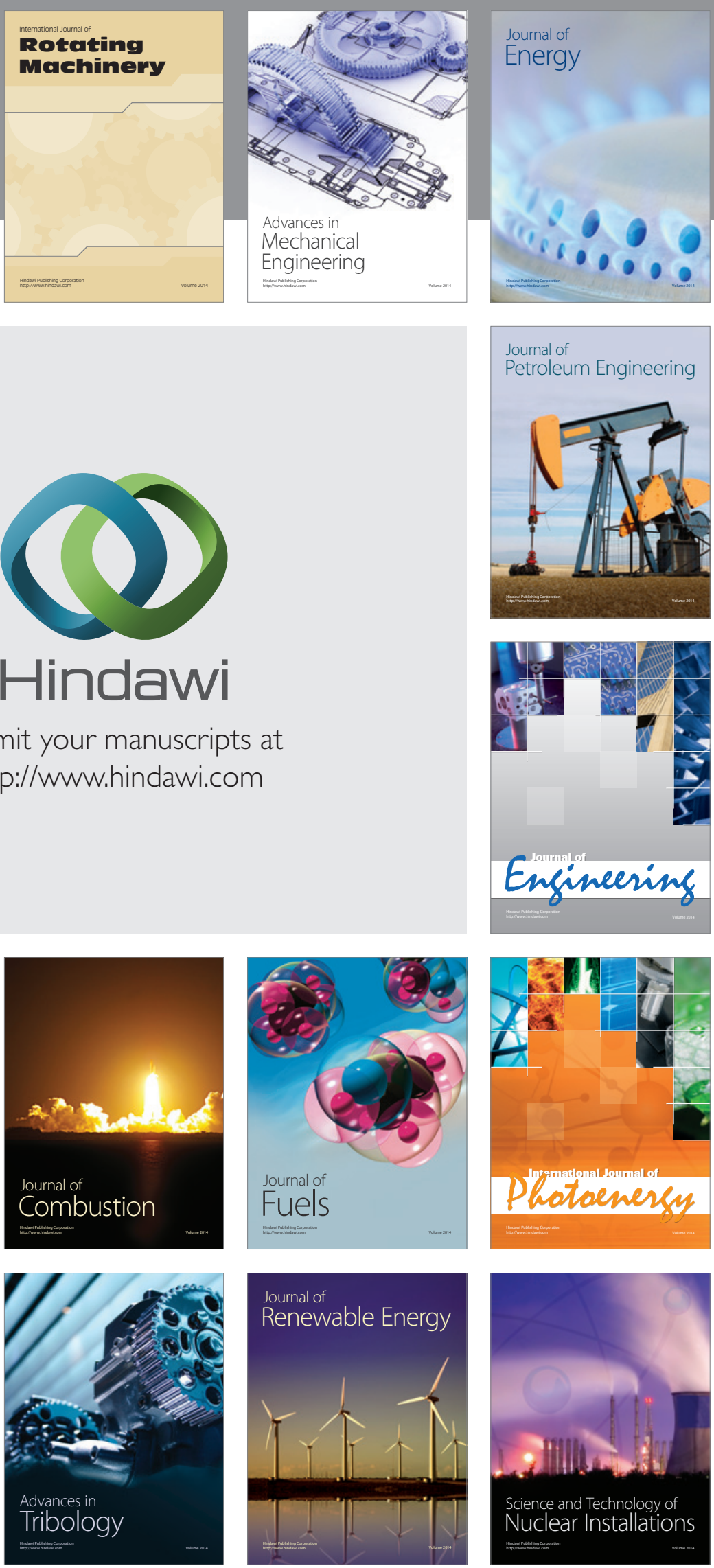